care will be with us for the foreseeable future, we submit that countries need to refocus their health workforce to tackle disease burden. Policies should strive to curb the dental-medical divide and to reduce social and service inequalities. The focus needs to be shifted from interventionist to preventive approaches. Preventive care should be customised for communities and carried out by teams drawn from the whole spectrum of health and social welfare professions. For such a paradigm shift, barriers from the entrenched profession will be a major challenge. Practical suggestions for a start on such reorientation would be to ban new dental schools in over-served countries and to train all members of putative oral healthcare teams together. 'The family that prays together stays together.'

S. Kumar, N. W. Johnson, Australia

1. Mathur M R, Singh A, Watt R. Addressing inequalities in oral health in India: need for skill mix in the dental workforce. J Family Med Prim Care 2015; 4: 200-202.

2. Jaiswal A K, Srinivas P, Suresh S. Dental manpower in India: changing trends since 1920. Int Dent J 2014; 64: 213-218.

DOI: $10.1038 /$ sj.bdj.2016.237

\section{Refugees in Jordan}

Sir, refugees in Jordan enjoy free access to schools, universities, clinics, hospitals, health and social care facilities, on par with their Jordanian brethren, stretching infrastructural capabilities to their absolute, maximum limits, and endangering oral and general health. There is risk of shortages in essential medical kits, medicines and vaccines. Oral health should always be viewed within the lens of general health. Oral diseases cause pain, lower quality of life, reduce productivity in terms of missing school, work and can cause systemic diseases (infective endocarditis, renal impairment). ${ }^{1}$ Moreover, they become obsolete especially in times of adversity. But what affects oral and general health is the social context that people live in. Health is produced not just by individual biology and medical interventions, but by conditions in the wider natural, social, economic, and political environments. ${ }^{2}$ And as $90 \%$ of refugees live across urban centres, it is vital to envisage a holistic paradigm of action that focuses on sustainable development and supports capacity building in host communities (national health systems, schools, community centres, etc), and tackles social injustices and inequities. By integrating oral health into strategies of promoting general health and by incorporating refugees' health into the healthcare systems of host communities, strategists can help Jordan remain resolute and unwavering in its humanitarian and peacekeeping missions, lifting huge burdens from the global community at large.

\section{F. Al Qutob, London}

1. Sheiham A. Oral health, general health and quality of life. Bull World Health Organ 2005; 83: 644

2. Fustukian S, Zwi A. Balancing imbalances: facilitating community perspectives in times of adversity. In Williams H A (ed). Special issue on Caring for those in crisis: integrating anthropology and public health in complex humanitarian emergencies. NAPA (National Association of Practising Anthropologists) Bulletin 2001; 21: 17-35. Available at: http://onlinelibrary. wiley.com/doi/10.1525/napa.2001.21.1.17/epdf (accessed March 2016).

DOI: 10.1038/sj.bdj.2016.238

\section{MOUTH CANCER}

\section{Acute necrotising sialometaplasia}

Sir, I read with interest the letter from Gogna et al. (BDJ 2015; 219: 560) regarding palatal mucosal necrosis after administration of a local anaesthetic palatal infiltration, and would like to highlight a similar case.

In August 2015 a 43-year-old Caucasian female with an unremarkable medical history was urgently referred to our oral and maxillofacial department by her dentist with suspected oral cancer. The patient reported an eight-day history of a painful ulcer on the hard palate, and on examination there was a $1.0 \times 1.5 \mathrm{~cm}$ diameter 'punched out' ulcer on the left posterior hard palate which extended down to bone. The defect contained loose, yellow sloughing tissue and the adjacent tissues were erythematous with raised, rolled margins (Fig. 1). An urgent incisional biopsy was performed which confirmed a diagnosis of acute necrotising sialometaplasia and excluded dysplasia. The patient was reassured of the diagnosis, advised to maintain good oral hygiene, and subsequently reviewed to assess for healing. The patient was discharged eight weeks later following complete resolution of the lesion.

Acute necrotising sialometaplasia is a rare, benign and self-limiting inflammatory condition of salivary gland tissue which occurs as a result of trauma causing the tissues to become ischaemic and necrotic. ${ }^{1}$ It typically

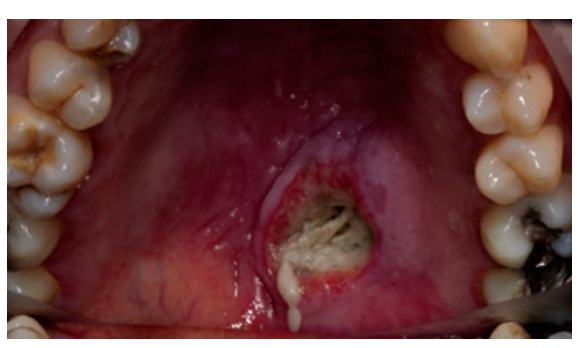

Fig. 1 The 'punched out' ulcer on the left posterior hard palate which extended down to bone presents as a unilateral necrotic ulcer on the hard palate but is often preceded by a firm, fluctuant and often painful swelling which can mimic a dental abscess. ${ }^{1}$ This condition has been associated with trauma, heavy smoking, excessive alcohol consumption and violent vomiting, such as in patients with bulimia, but can also occur following palatal infiltrations. ${ }^{2}$ As Dr Gogna's patient did not receive a biopsy to confirm a diagnosis, I wonder if acute necrotising sialometaplasia could have been a differential diagnosis to consider? The most significant issue to highlight is that it can mimic malignancy, both clinically and histologically, which could result in an incorrect diagnosis and unnecessary intervention. The condition is self-limiting and does not require treatment besides supportive measures, often healing spontaneously within 4-10 weeks without complication. ${ }^{1}$

Should this condition present in general dental practice, then an urgent referral to the oral and maxillofacial or oral medicine team for a second opinion is advisable, as an incisional biopsy will often be undertaken to confirm a diagnosis and exclude malignancy.

A. Davies-House, Liverpool

1. Randhawa T, Varghese I, Shameena P M, Sudha S, Nair R G. Necrotizing sialometaplasia of tongue. J Oral Maxillofac Pathol 2009; 13: 35-37.

2. Carlson D L. Necrotizing sialometaplasia: a practi$\mathrm{cal}$ approach to the diagnosis. Arch Pathol Lab Med 2009; 133: 692-698.

DOI: 10.1038/sj.bdj.2016.239

\section{DENTAL STUDENTS}

\section{Humanitarian endeavours}

Sir, what an impact! And what a riveting piece of journalism: the personal account in the $B D J$ of dental students going to Northern France to assist voluntarily in the dental well-being of migrants: no pay and looking after people in atrocious conditions for whom they had no legal responsibility but felt the call of common humanity to do what they could to help. ${ }^{1}$

Was it foolhardy? Possibly. Was it brave? Undoubtedly - we read about the violence and the protection rackets with horror. A big thank you from all of us with an interest in dentistry for such a humanitarian endeavour.

Now may we look forward please to an equally revealing article, illustrated, of the experiences of the junior hospital dentists while on their strike days, refusing to treat patients who they were contracted to look after and helping the junior doctors in postponing thousands upon thousands of appointments, each of which will have meant a great deal to the victims? 